\title{
Treatment Outcome of
}

\section{Pharmacokinetics-Based Dosing of Docetaxel and Fluorouracil in Advanced Head and Neck Cancer Patients}

\author{
Abdelhamid M. Fouad1*, Magdy M. Saber1, Yahia M. Ismail1, Yasser A. Sallam1, \\ Tarek M. Shouman², Reham A. A. Elshimy33, Ahmed Abo Gabal2 \\ ${ }^{1}$ Department of Medical Oncology, National Cancer Institute, Cairo University, Cairo, Egypt \\ ${ }^{2}$ Department of Radiation Oncology, National Cancer Institute, Cairo University, Cairo, Egypt \\ ${ }^{3}$ Department of Clinical and Chemical Pathology, National Cancer Institute, Cairo University, Cairo, Egypt \\ Email: *abdelhamid.fouad@nci.cu.edu.eg
}

How to cite this paper: Fouad, A.M., Saber, M.M., Ismail, Y.M., Sallam, Y.A., Shouman, T.M., Elshimy, R.A.A. and Gabal, A.A. (2018) Treatment Outcome of Pharmacokinetics-Based Dosing of Docetaxel and Fluorouracil in Advanced Head and Neck Cancer Patients. Journal of Cancer Therapy, 9, 998-1010.

https://doi.org/10.4236/jct.2018.912082

Received: November 21, 2018

Accepted: December 15, 2018

Published: December 18, 2018

Copyright $\odot 2018$ by authors and Scientific Research Publishing Inc. This work is licensed under the Creative Commons Attribution International License (CC BY 4.0).

http://creativecommons.org/licenses/by/4.0/

\begin{abstract}
Introduction: Docetaxel, Cisplatin and 5-Fluorouracil (DPF) became the standard induction chemotherapy in advanced Head and Neck Cancer (HNC) but associated with high toxicity rate. Several studies reported higher response rates with better tolerability when chemotherapy dose is calculated based on Pharmacokinetics (PK) versus conventional Body Surface Area (BSA). Patien ts and Methods: Thirty nine patients with stage III and IV HNC who received induction DPF were included in the study. Dose of cycle 1 was BSA-based then Docetaxel and 5-FU doses were PK-adjusted starting from cycle 2 whereas Cisplatin dose was BSA-based throughout the study. Results: After median follow up period of 14 months the median overall survival (OS) and progression free survival (PFS) were 15.1 and 10.6 months respectively. Twenty nine patients were available for response assessment. Seven patients $(24.1 \%)$ achieved complete response while partial response encountered in 19 patients (65.5\%) with and Overall response rate of $89.6 \%$. Both treatment related side effects and mortality significantly decreased after the application of PK dose adjustments (p-value 0.007 and 0.01 respectively). Conclusion: PK-guided dose adjustments of 5-FU and Docetaxel in D PF regimen can significantly decrease the treatment related side effects and mortality without compromising the tumor response rate. A randomized clinical trial is needed to compare the PK-guided dose adjustment with the standard BSA based protocol.
\end{abstract}




\section{Keywords}

Head and Neck Cancer, D PF, Docetaxel, Fluorouracil, Phar macokinetics Dose Adjustment

\section{Introduction}

Head and Neck Cancers (HNCs) are heterogeneous group of cancers. That may differ in location, pathogenesis, tumor biology, treatment, prognosis and effect on quality of life [1]. It was estimated that HNCs comprise $2 \%-3 \%$ of all cancers in the United States and account for $1 \%-2 \%$ of all cancer deaths [2]. In Egypt, HNC represents about $5 \%$ of all malignant tumors [3].

The Docetaxel, Cisplatin and 5-fluorouracil (5-FU) regimen (DPF) is the standard induction regimen in advanced HNC since the publication of the TAX323 [4] and TAX324 studies [5]. On the other hand, they are associated with high hematologic toxicity and a high complication rate [4] [5].

Chemotherapy dosing is based on body surface area (BSA). The BSA-based dose for any drug is recommended by the manufacturer according to the maximum tolerated dose (MTD) achieved during phase I studies. But there is actually no exact scientific basis for the use of BSA for chemotherapeutic drugs, and several studies have shown that this approach is not valid. BSA-based dosing is associated with drug plasma level variability up to 30 -fold. Solid evidence exists that this inter- and intra-patient pharmacokinetic (PK) variability of anticanceragents is a major contributor to toxicity and treatment failure [6].

Former studies reported that $20 \%-30 \%$ of patients treated with BSA-based 5-FU dosing have drug exposure levels within a previously established therapeutic range [area under the concentration-time curve (AUC) $20-25 \mathrm{mg} / \mathrm{h} / \mathrm{L}$ ], whereas approximately $40 \%-60 \%$ and $10 \%-20 \%$ are under and over this therapeutic AUC threshold respectively. PK-guided 5-FU dosing has not been widely incorporated into clinical practice, because of the lack of data that support this approach [7]. Also there is lack of prospective studies that clarify the concept of modifying the Docetaxel dose based on drug PKs to achieve the target AUC. We proposed this study aiming to investigate the application of PKguided 5-FU and Docetaxel dosing and to evaluate its effect on treatment outcome and toxicity profile.

\section{Patients and Methods}

\subsection{Patients}

This prospective study was conducted at the Medical Oncology department, National Cancer Institute of Egypt, Cairo University. All the patients with HNC stages III \& IV who were candidate for induction chemotherapy (DPF) during the period from April 2013 to April 2014 and approved to participate in the trial were included in the study. The study included 39 patients and they were fol- 
lowed till December 2016. Eligibility criteria were: Age 18 - 70 years, histologically confirmed diagnosis of stage III \& IV HNC (excluding hematopoietic, lymphoprolefrative, sarcoma, thyroid and primary skin cancer), Eastern Cooperative Oncology Group (ECOG) performance status (PS) $\leq 2$, with adequate bone marrow, liver and kidney functions. Ineligibility criteria were: pregnancy or lactation, serious illnesses like myocardial infarction within 6 months prior to study entry, history of significant neurologic or psychiatric disorders including dementia or seizures and patients with active uncontrolled infection.

\subsection{Treatment and PK-Based Dose Adjustments}

All of the patients were planned to receive three cycles of DPF regimen. At the first cycle, the doses of the drugs were prescribed based on the patient's body surface area. The dose of Docetaxel and Cisplatin was $75 \mathrm{mg} / \mathrm{m}^{2}$ for each drug and both of them were delivered on day 1 of the cycle while as regards 5-FU the dose was $1000 \mathrm{mg} / \mathrm{m}^{2} /$ day and it was delivered as continuous intravenous infusion (CIVI) over 24 hours from day 1 to 4 of the cycle. Subsequent cycles were repeated every 3 weeks. Docetaxel and 5-FU CIVI doses were adjusted starting from the second cycle and onwards using a PK-guided dose-adjustment algorithm based on plasma concentration results of the preceding cycle that was expressed as AUC dose/h/L (Table 1). Cisplatin dosage remained the same throughout the treatment as there were no available kits to perform PK-guided

Table 1. 5-FU and docetaxel dose adjustment algorithm.

\begin{tabular}{|c|c|}
\hline \multicolumn{2}{|c|}{ 5-FU adjustment [9] } \\
\hline $\operatorname{AUC}(\mathrm{mg} / \mathrm{h} / \mathrm{L})$ & Dose adjustment \\
\hline$\geq 45$ & Reduce by $30 \%$ \\
\hline $42-44$ & Reduce by $25 \%$ \\
\hline $39-41$ & Reduce by $20 \%$ \\
\hline $36-38$ & Reduce by $10 \%$ \\
\hline $25-35$ & NO CHANGE NEEDED \\
\hline $22-24$ & Increase by $10 \%$ \\
\hline $19-21$ & Increase by $20 \%$ \\
\hline $16-18$ & Increase by $25 \%$ \\
\hline $8-15$ & Increase by $30 \%$ \\
\hline \multicolumn{2}{|c|}{ Docetaxel adjustment [10] } \\
\hline $\operatorname{AUC}(\mathrm{mg} / \mathrm{h} / \mathrm{L})$ & Dose adjustment \\
\hline$>5.5$ & Reduce by $25 \%$ \\
\hline $4.5-5.5$ & Reduce by $10 \%$ \\
\hline $3.5-4.5$ & NO CHANGE NEEDED \\
\hline $1.5-3.5$ & Increase by $10 \%$ \\
\hline$<1.5$ & Increase by $25 \%$ \\
\hline
\end{tabular}


Cisplatin dose adjustment. Further treatment after the induction DPF was tailored according to response i.e. those who achieved good response received local therapy (surgery or concomitant chemoradiotherapy) while non-responders received palliative treatment.

During cycles 1 - 3, a peripheral blood sample was obtained for the measurement of the plasma level (mg/L) of 5-FU and Docetaxel which was used later on to calculate the plasma concentration or AUC (dose/h/L) of the drugs. The plasma level of both drugs was measured carefully using the following steps: Regarding 5-FU at least 18 hours after the start of CIVI $2 \mathrm{ml}$ blood sample was withdrawn into an ethylene diamine tetra acetic acid (EDTA) tube. A stabilizing agent [derivative of uracil with properties that irreversibly inhibit Dihydropyrimidine dehydrogenase (DPD)] was added to the sample immediately. The sample was used for AUC analysis using immunoassay-based technique. ForDocetaxel, two $2 \mathrm{ml}$ samples were withdrawn into an EDTA tubes, first was in the last 5 minutes of infusion, whereas second was 1 hour after end of infusion. AUC for 5-FU was calculated by multiplying the steady-state concentration (CSS) by time of continuous infusion (TCI): AUC $=$ Css $\times$ TCI. AUC for Docetaxel was calculated using limited samples strategy where the AUC was estimated from two samples, one of them during and one other after the infusion [8].

\subsection{Follow up, Response and Toxicity Assessment}

Patients were considered eligible for response analysis if they completed three cycles of planned DPF. Disease response was assessed at the end of cycle three then every 3 months. Responses were assessed using the Response Evaluation Criteria in Solid Tumors (RECIST V1.1) criteria [11]. During follow up complete physical examinations was performed and local imaging (CT or MRI) was requested. Toxicity assessment was done using the National Cancer Institute Common Terminology Criteria for Adverse Events (CTCAE) version 4.0 [12]. Patients were followed-up for a minimum period of 12 months for survival assessment.

\subsection{Statistical Methods}

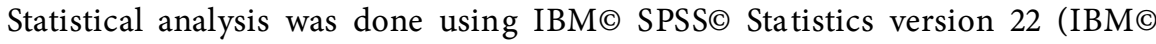
Corp., Armonk, NY, USA). Numerical data were expressed as mean and standard deviation or median and range as appropriate. Qualitative data were expressed as frequency and percentage. Chi-square test was used to compare toxicity between different cycles. Survival analysis was done using Kaplan-Meier method and comparison between survival curves was done using log-rank test. All tests were two-tailed. A p-value $<0.05$ was considered significant. Progression free survival (PFS) was defined as the time measured in Months from starting first cycle of treatment until disease progression or death from any cause. Overall survival (OS) was calculated from the date of starting first cycle of treatment until death or last visit. 


\section{Results}

\subsection{Patients Characteristics}

Thirty nine patients were enrolled in this study. The mean age of the patients was $46.7 \pm 9.7$ years (range 24 - 68). More than half of the patients were females (53.8\%). The majority of the patients at the study entry had PS 1 (97.4\%) and the smoking history was depicted in $30.8 \%$ of them. Presentation with head and neck lump was the most common presenting complaint (66.7\%). Pa tient characteristics were summarized at (Table 2).

\subsection{Tumor Characteristics}

The tumor characteristics at the time of diagnosis are shown in (Table 3). Nasopharyngeal cancer was encountered in 11 patients (28.2\%). Squamous cell carcinoma was the predominant histological subtype found in $58.9 \%$ of cases. G II tumors were the dominant grade found in $46.2 \%$ of cases. The majority of our cases presented with advanced tumor $(\mathrm{T})$ and nodal $(\mathrm{N})$ stage where T3 \& T4 encountered in $69.3 \%$ while N2 \& N3 in $51.2 \%$.

Table 2. Characteristics of the study patients.

\begin{tabular}{|c|c|}
\hline Parameter & Number (\%) \\
\hline \multicolumn{2}{|l|}{ Age } \\
\hline Mean \pm Standard deviation & $46.7 \pm 9.7$ \\
\hline Median (Range) & $47(24-68)$ \\
\hline \multicolumn{2}{|l|}{ Gender } \\
\hline Female & $21(53.8 \%)$ \\
\hline Male & $18(46.2 \%)$ \\
\hline \multicolumn{2}{|l|}{ Comorbidity } \\
\hline Diabetes & $2(5.1 \%)$ \\
\hline Hypertension & $3(7.7 \%)$ \\
\hline Smoking & $12(30.8 \%)$ \\
\hline \multicolumn{2}{|l|}{ Performance Status } \\
\hline 1 & $38(97.4 \%)$ \\
\hline 2 & $1(2.6 \%)$ \\
\hline \multicolumn{2}{|l|}{ Presenting Complaint } \\
\hline Headache & $9(23.1 \%)$ \\
\hline Pain & $10(25.6 \%)$ \\
\hline Blurring of vision & $2(5.1 \%)$ \\
\hline Nasal obstruction & $8(20.5 \%)$ \\
\hline Mass & $26(66.7 \%)$ \\
\hline Dysphagia & $9(23.1 \%)$ \\
\hline Hoarseness of voice & $7(17.9 \%)$ \\
\hline
\end{tabular}


Table 3. Tumor characteristics of the study patients.

\begin{tabular}{|c|c|}
\hline Parameter & Number (\%) \\
\hline \multicolumn{2}{|l|}{ Site } \\
\hline Nasopharynx & $11(28.2 \%)$ \\
\hline Oropharynx & $4(10.3 \%)$ \\
\hline Hypopharynx & $1(2.6 \%)$ \\
\hline Supraglottic larynx & $1(2.6 \%)$ \\
\hline Glottic larynx & $4(10.3 \%)$ \\
\hline Postcricoid & $6(15.4 \%)$ \\
\hline Mandible & $5(12.8 \%)$ \\
\hline Maxilla & $3(7.7 \%)$ \\
\hline Tongue & $3(7.7 \%)$ \\
\hline Sino-nasal & $1(2.6 \%)$ \\
\hline \multicolumn{2}{|l|}{ Pathological type } \\
\hline Squamous cell carcinoma & $23(58.9 \%)$ \\
\hline Adenocarcinoma & $14(35.9 \%)$ \\
\hline Mucoepidermoid & $1(2.6 \%)$ \\
\hline Adenomucinous & $1(2.6 \%)$ \\
\hline \multicolumn{2}{|l|}{ Grade } \\
\hline I & $4(10.3 \%)$ \\
\hline II & $18(46.2 \%)$ \\
\hline III & $7(17.9 \%)$ \\
\hline IV & $10(25.6 \%)$ \\
\hline \multicolumn{2}{|l|}{ T-stage } \\
\hline $\mathrm{T} 1$ & $2(5.1 \%)$ \\
\hline $\mathrm{T} 2$ & $10(25.6 \%)$ \\
\hline $\mathrm{T} 3$ & $14(35.9 \%)$ \\
\hline $\mathrm{T} 4 \mathrm{a}$ & $9(23.1 \%)$ \\
\hline $\mathrm{T} 4 \mathrm{~b}$ & $4(10.3 \%)$ \\
\hline \multicolumn{2}{|l|}{$\mathrm{N}$-stage } \\
\hline No & $11(28.2 \%)$ \\
\hline N1 & $8(20.6 \%)$ \\
\hline $\mathrm{N} 2$ & $10(25.6 \%)$ \\
\hline N3 & $10(25.6 \%)$ \\
\hline \multicolumn{2}{|l|}{ TNM stage } \\
\hline III & $5(12.8 \%)$ \\
\hline IVA & $19(48.7 \%)$ \\
\hline IVB & $15(38.5 \%)$ \\
\hline
\end{tabular}




\subsection{Treatment}

Three cycles of induction DPF were prescribed to all of the patients who were included in the study. The first cycle was delivered successfully to all of them however only 30 and 29 patients were able to receive the second and third cycles respectively. Eight of the ten patients who did not complete the treatment died and the other two patients lost follow up before the subsequent cycles.

\subsection{Drug Pharmacokinetic Characteristics and Dose Adjustments}

\section{Docetaxel:}

After the first cycle, the patients who had low, high and targeted plasma concentration of Docetaxel were 13, 14 and 9 respectively. Three patients did not get their results due to lab error (i.e. beyond stability blood sample). Thirty patients were able to receive the second cycle of DPF and their plasma concentration of Docetaxel was re-assessed. The patients who had low, high and targeted plasma concentration of Docetaxel were 9, 4 and 15 respectively while it couldn't be measured for 2 patients due to lab error. The third cycle was received by $29 \mathrm{pa}-$ tients. Twenty three patients had target plasma concentration, three patients had low plasma concentration and another three patients had high plasma concentration of Docetaxel.

Based on plasma concentrations of Docetaxel, the following adjustments in Docetaxel dose in the subsequent cycle were done: No dose change for the patients with either target plasma concentration or lab error, dose reduction for the patients with high plasma concentrations and dose escalation for those patients with low plasma concentrations.

The median doses of Docetaxel given in the first cycle, second and third cycle were $127,127.5$ and $134 \mathrm{mg}$ respectively and the Docetaxel dose necessary to successfully achieving the target AUC at cycle 3 ranged from $44.9 \%$ to $137.8 \%$ of the standard dose $\left(75 \mathrm{mg} / \mathrm{m}^{2}\right)$.

5-FU:

After the first cycle, the patients who had low, high and targeted plasma concentration of 5-FU were 10, 9 and 7 respectively. Thirteen patients did not get their results due to lab error (i.e. beyond stability blood sample). Thirty patients were able to receive the second cycle of DPF and their plasma concentration of 5-FU was re-assessed. The patients who had low, high and targeted plasma concentration of 5-FU were 5, 7 and 11 respectively while it couldn't be measured for 7 patients due to lab error. The third cycle was received by 29 patients. Twenty patients had target plasma concentration, two patients had high plasma concentration and none of the patients had low plasma concentration of 5-FU. Again, seven patients did not get their results due to lab error (i.e. beyond stability blood sample).

Based on plasma concentrations of 5-FU, the following adjustments in 5-FU dose in the subsequent cycle were done: No dose change for the patients with either target plasma concentration or lab error, dose reduction for the patients 
with high plasma concentrations and dose escalation for those patients with low plasma concentrations.

The median doses of 5-FU given in the first cycle, second and third cycle were 1700,1685 and $1700 \mathrm{mg}$, respectively and the 5-FU dose necessary to achieve the target AUC at cycle 3 ranged from $31.2 \%$ to $147 \%$ of the standard dose.

Cisplatin:

Cisplatin dosage was based on BSA in the three cycles and was given as 75 $\mathrm{mg} / \mathrm{m} 2$ on day 1 .

\section{Toxicity}

The treatment related toxicity was evaluated after each cycle. Two patients lost follow up after the first cycle and were not included in the toxicity assessment. Diarrhea, mucositis and neuropathy were the most frequent toxic events and occurred mainly after the first cycle of treatment. Treatment related deaths was encountered in 8 patients and were due to febrile neutropenia and septic shock and all of them had high plasma concentrations to Docetaxel and/or 5-FU. Both severe (grade III \& IV) treatment related side effects and mortality significantly decreased after the application of PK dose adjustments compared to the first cycle which was prescribed based on the patients' BSA (Table 4, Figure 1).

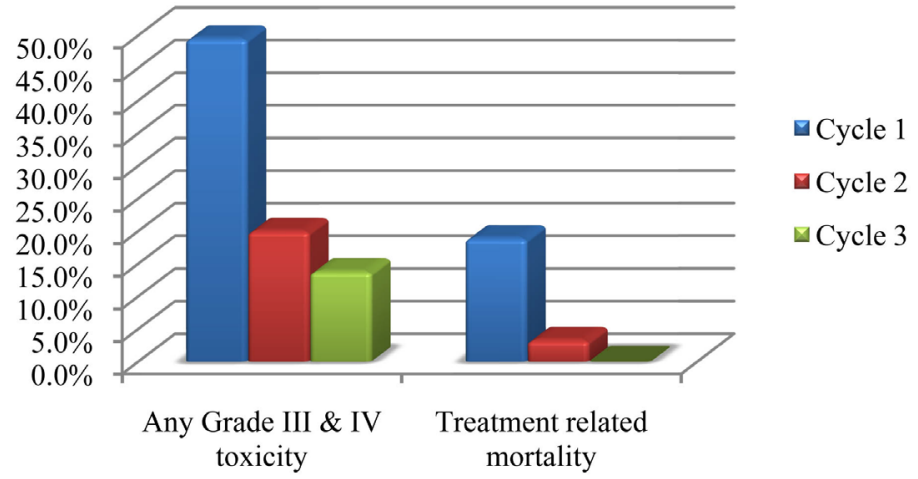

Figure 1. Toxicity and treatment related mortality in relation to each cycle.

Table 4. Adverse events observed for the 3 cycles of treatment.

\begin{tabular}{ccccc}
\hline \multirow{2}{*}{ No. of assessed patients } & Cycle 1 & Cycle 2 & Cycle 3 & \\
\cline { 2 - 4 } & 37 & 30 & 29 & \\
\hline Events & Number (\%) & Number (\%) & Number (\%) & P-value \\
\hline Any Grade III \& IV toxicity & $17(49.5 \%)$ & $6(20 \%)$ & $4(13.8 \%)$ & $\mathbf{0 . 0 0 7}$ \\
Diarrhea & $8(21.6 \%)$ & $4(13.3 \%)$ & $2(6.9 \%)$ & 0.236 \\
Mucositis & $9(24.3 \%)$ & $3(10 \%)$ & $1(3.4 \%)$ & $\mathbf{0 . 0 3 8}$ \\
Myelosuppression & $12(32.4 \%)$ & $2(6.7 \%)$ & $3(10.3 \%)$ & 0.01 \\
Neuropathy & $2(5.4 \%)$ & $1(3.3 \%)$ & $1(3.4 \%)$ & 0.89 \\
Nausea \& Vomiting & $2(5.4 \%)$ & $2(6.7 \%)$ & $0(0.0 \%)$ & 0.392 \\
Treatment related mortality & $7(18.9 \%)$ & $1(3.3 \%)$ & $0(0.0 \%)$ & 0.01 \\
\hline
\end{tabular}

*Treat ment rel ated mortality were due to febrile neutropenia and septic shock. 


\section{Response}

Twenty nine patients completed full 3 cycles of DPF and were assessed for response using RECIST criteria. Seven patients achieved complete response (CR), whereas 19 had partial response (PR), accounting for $24.1 \%$ and $65.5 \%$, respectively, with an objective response rate (ORR) of $89.6 \%$. Only 3 patients did not respond well to the treatment, 2 of them had stable disease and the last one had progression of his disease. Since most of the patients (89.6\%) achieved good response to the treatment no further analysis was done to define prognostic factors for response.

\section{Survival}

After a median follow up period of 14 months (range 1.0 - 43.9), the median PFS for the whole group was 10.6 months (95\% confidence interval (CI): 6.2 14.9 ) and the OS was 15.1 months (95\% CI: 10.9 - 19.2). Cumulative PFS and OS at the end of study (36 months) were $29.7 \%$ and $31.1 \%$ respectively (Table $5 \&$ Figure 2).

Patients with nasopharyngeal tumors had significantly superior PFS and OS compared to the patients with HNC at other sites (p-value 0.01 and 0.006 respectively). Early T-stage had a borderline significance as a good prognostic factor for PFS (p-value 0.05 ) while developing G III \& IV toxicity at any cycle also had a borderline significant poor impact on OS $(\mathrm{p}=0.05)$.
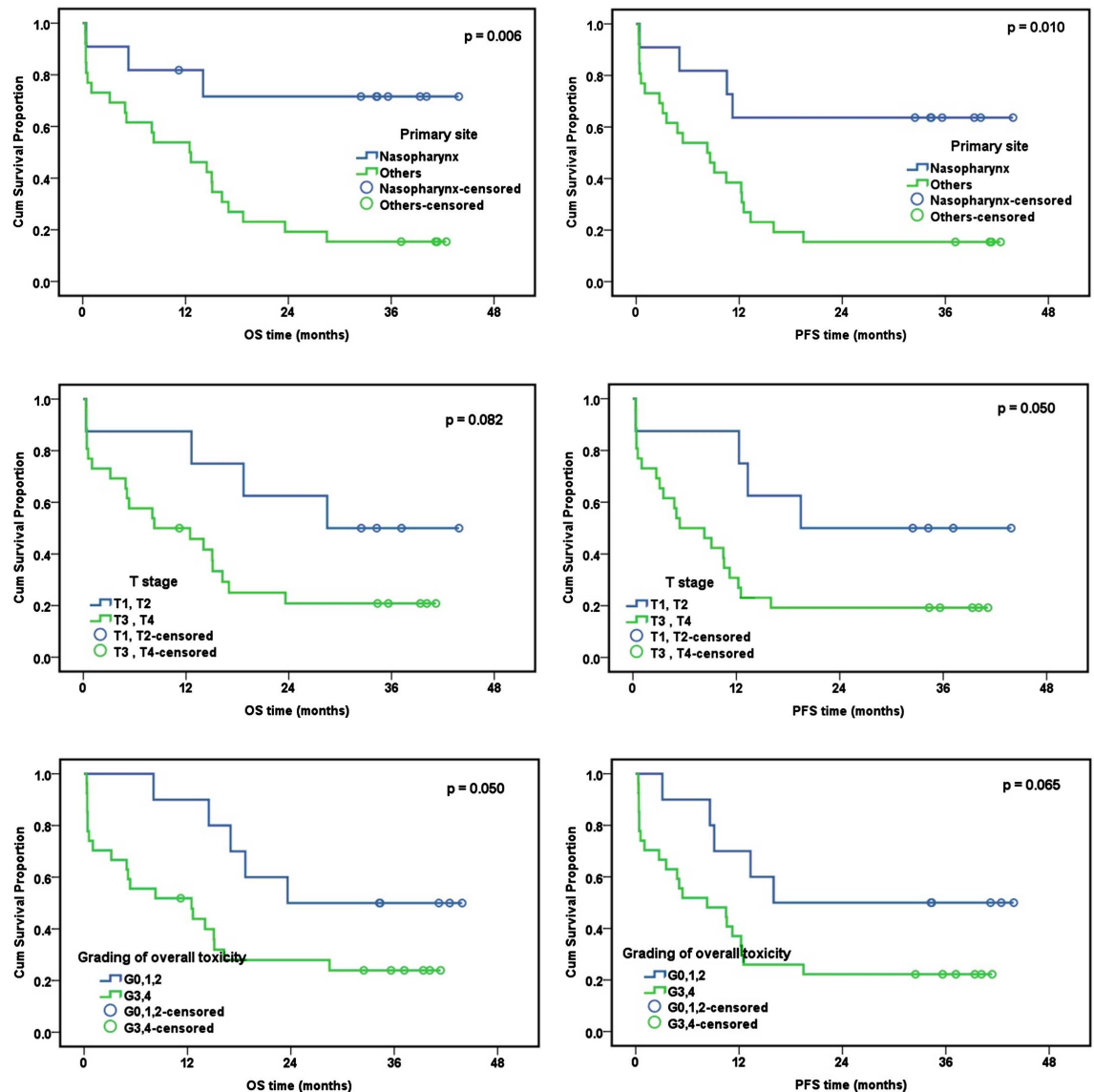

Figure 2. Relation between clinicopathological factors, toxicity with PFS and OS. 
Table 5. Relation between clinicopathological factors, toxicity with PFS and OS.

\begin{tabular}{|c|c|c|c|c|c|c|c|c|c|}
\hline \multirow[b]{2}{*}{$\begin{array}{l}\text { Prognostic } \\
\text { factors }\end{array}$} & \multirow[b]{2}{*}{$\begin{array}{c}\text { Number of } \\
\text { patients }\end{array}$} & \multicolumn{4}{|c|}{ PFS } & \multicolumn{4}{|c|}{ os } \\
\hline & & $\begin{array}{c}\text { PFS at } 18 \\
\text { months }\end{array}$ & $\begin{array}{l}\text { PFS at } 36 \\
\text { months }\end{array}$ & $\begin{array}{c}\text { Median PFS } \\
\text { months }\end{array}$ & $\mathrm{P}$-value & $\begin{array}{c}\text { OS at } \\
18 \text { months }\end{array}$ & $\begin{array}{c}\text { OS at } \\
36 \text { months }\end{array}$ & $\begin{array}{c}\text { Median OS } \\
\text { months }\end{array}$ & $P$-value \\
\hline Whole group & 39 & $32.4 \%$ & $29.7 \%$ & 10.6 & & $39.6 \%$ & $31.1 \%$ & 15.1 & \\
\hline \multicolumn{10}{|l|}{ Age } \\
\hline$\leq 47$ & 20 & $25.0 \%$ & $25.0 \%$ & 8.6 & 0.45 & $33.0 \%$ & $27.5 \%$ & 14.0 & 0.604 \\
\hline$>47$ & 19 & $35.3 \%$ & $35.3 \%$ & 12.5 & & $47.1 \%$ & $35.3 \%$ & 16.3 & \\
\hline \multicolumn{10}{|l|}{ Sex } \\
\hline Male & 18 & $17.6 \%$ & $17.6 \%$ & 10.5 & 0.22 & $25.9 \%$ & $19.4 \%$ & 14.0 & 0.258 \\
\hline Female & 21 & $40.0 \%$ & $40.0 \%$ & 12.3 & & $50.0 \%$ & $40.0 \%$ & 15.0 & \\
\hline \multicolumn{10}{|l|}{ Smoking } \\
\hline Non-smoker & 27 & $34.6 \%$ & $34.6 \%$ & 9.1 & 0.65 & $45.3 \%$ & $37.1 \%$ & 15.0 & 0.486 \\
\hline Smoker & 12 & $18.2 \%$ & $18.2 \%$ & 10.6 & & $27.3 \%$ & $18.2 \%$ & 14.5 & \\
\hline \multicolumn{10}{|l|}{ Primary site } \\
\hline Nasopharynx & 11 & $63.6 \%$ & $63.6 \%$ & - & 0.01 & $71.6 \%$ & $71.7 \%$ & - & 0.006 \\
\hline Other & 28 & $15.4 \%$ & $15.4 \%$ & 8.2 & & $26.9 \%$ & $15.4 \%$ & 12.7 & \\
\hline \multicolumn{10}{|l|}{ Histology } \\
\hline SCC & 23 & $18.2 \%$ & $18.2 \%$ & 8.6 & 0.089 & $31.8 \%$ & $18.2 \%$ & 12.6 & 0.071 \\
\hline Others & 16 & $46.7 \%$ & $46.7 \%$ & 16.0 & & $51.9 \%$ & $51.9 \%$ & - & \\
\hline \multicolumn{10}{|l|}{ Grade } \\
\hline I and II & 22 & $21.1 \%$ & $21.1 \%$ & 5.4 & 0.061 & $31.6 \%$ & $21.1 \%$ & 8.3 & 0.072 \\
\hline III and IV & 17 & $41.2 \%$ & $41.2 \%$ & 13.3 & & $50.7 \%$ & $44.3 \%$ & 18.7 & \\
\hline \multicolumn{10}{|l|}{ T-stage } \\
\hline $\mathrm{T} 1$ and $\mathrm{T} 2$ & 12 & $50.0 \%$ & $50.0 \%$ & 19.5 & 0.05 & $62.5 \%$ & $50.0 \%$ & 28.5 & 0.082 \\
\hline $\mathrm{T} 3$ and $\mathrm{T} 4$ & 27 & $19.2 \%$ & $19.2 \%$ & 5.4 & & $25.0 \%$ & $20.8 \%$ & 8.3 & \\
\hline \multicolumn{10}{|l|}{$\mathrm{N}$-stage } \\
\hline N0 and N1 & 19 & $23.5 \%$ & $23.5 \%$ & 8.3 & 0.41 & $29.4 \%$ & $23.5 \%$ & 12.5 & 0.374 \\
\hline $\mathrm{N} 2$ and $\mathrm{N} 3$ & 20 & $35.0 \%$ & $35.0 \%$ & 11.2 & & $43.1 \%$ & $37.7 \%$ & 16.3 & \\
\hline \multicolumn{10}{|l|}{ Grade 3 - 4} \\
\hline \multicolumn{10}{|l|}{ Toxicity* } \\
\hline No & 12 & $50.0 \%$ & $50.0 \%$ & 16.0 & 0.065 & $60.0 \%$ & $50.0 \%$ & 23.6 & 0.05 \\
\hline Yes & 25 & $25.9 \%$ & $22.2 \%$ & 8.3 & & $27.9 \%$ & $23.9 \%$ & 15.0 & \\
\hline
\end{tabular}

*Analysis was done on the 37 patients who were assessed for toxicity. Patients who developed toxicity at any cycle where grouped tog ether. Abbreviations: OS = overall survival; PFS = progression free survival; SCC $=$ squamous cell carcinoma.

\section{Discussion}

While therapeutic options for HNCs have improved over the past 30 years, the survival for patients with advanced HNCs remained poor with high treatment related toxicity [13]. The DPF regimen is associated with extensive hematologic 
toxicity and a high complication rates resulting in treatment delays and delivery of less number of planned cycles with subsequent impairment of treatment outcome [4].

Santini et al. [14], Fety et al. [15] and Gamelin et al. [16] prospectively studied 5-FU dose adjustment based on PK aiming to predict safe dose intensification with less toxic adverse effects; however, there is lack of prospective studies that tried to clarify the concept of modifying the dose of Docetaxel-based PKs to improve its therapeutic index [10]. To the best of our knowledge, our study is the first to prospectively investigate PK-based dose adjustment of both Docetaxel and 5-FU in DPF regimen used in advanced HNC.

Santini et al. [14] and Fety et al. [15] compared the effect of PK-based 5-FU dose adjustment in Cisplatin/5-FU (PF) regimen in advanced HNC to BSA-based PF (two arm studies).In the former study the CR in PK arm was 47.0 vs $31.0 \%$ in the BSA arm $(P<0.050)$, whereas in the second study ORR in PK arm was 81.7 vs $77.2 \%$ in BSA arm $(P=0.030)$, while in our study ORR was $89.6 \%$. ORR in our study was higher than that achieved by Vermorken et al. [4] (67.8\%) and Posner et al. [5] (72.0\%) who used BSA-based DPF dosing in advanced HNC. Our results concur with that reported in the meta-analysis do ne by Fang et al. [17] and indicated that PK-guided strategy significantly improved the ORR compared with BSA-guided strategy $(P<0.0001)$. Matching with these results; Gamelin et al. [16] reported ORR in the PK arm was $33.6 \%$ vs $18.3 \%$ in the BSA $\operatorname{arm}(P=0.0004)$.

In respect to DPF-associated toxicities observed in our study, they were consistent with that reported in other literature used BSA-based dosing including myelosuppression, diarrhea, mucositis, hand and foot syndrome, nausea, vomiting, neuropathy and febrile neutropenia. In the current study the treatment related serious side effects (G III \& IV) and treatment related mortality after second and third cycles(PK-based) were significantly lowered when compared to that occurred after first cycle (BSA-based) $(P=0.007$ and 0.01 , respectively). These findings again are similar to the work of Santini et al. [14] and Fety et al. [15] where the incidence of GIII \& IV toxicities were significantly lower in PK arm vs BSA arm. The frequency of G III \& IV myelosuppression (neutropenia) after the third cycle in our study was lower in patients treated with PK-guided DPF dosing when compared with BSA-guided DPF dosing used in Vermorken et al. [4] and Posner et al. [5] (10.3\% vs $76.9 \%$ vs $83 \%$, respectively).

The correlation between age and PK dose adjustment was presented in ASCO 2005 by ten Tije et al. [18] and they found that Docetaxel plasma PKs are unaltered in elderly patients, yet they appeared to be more sensitive to Docetaxel-induced neutropenia. In our trial this correlation was not done due to the percentage of patients aged $\geq 65$ years was only $2.6 \%$.

In our study the Docetaxel dose necessary to successfully achieving the target AUC at cycle 3 ranged from $44.9 \%$ to $137.8 \%$ of the standard dose $\left(75 \mathrm{mg} / \mathrm{m}^{2}\right)$. While the 5-FU dose necessary to achieve the target AUC at cycle 3 ranged from $31.2 \%$ to $147 \%$ of the standard dose $\left(1000 \mathrm{mg} / \mathrm{m}^{2}\right)$. We attributed this finding to 
the large intra-patient variability in Docetaxel and 5-FU exposure and this finding underline that no standard dose could be applied for all patients due to different plasma levels of drugs in each patient. The intra-patient variability may be due to administration time (circadian rhythm), PK sampling time, diet, concomitant medications and other enviro nmental factors [9].

The main limitation of our study is the single-arm design, which did not allow for direct comparison of BSA\& PK dosing strategies (in 2 different arms) regarding toxicity, tolerance and efficacy.

Also, the number of non evaluable (beyond stability) samples throughout the course of the study was high and this may be due to samples being withdrawn before or after the exact time of infusion and infusion time error reflecting the challenges of conducting this dosing approach. This suggests that experience and training would be necessary to correctly implement this dosing approach.

\section{Conclusion}

PK-based dose adjustment of Docetaxel and 5-FU in DPF regimen in advanced HNC significantly lowered serious toxicities and treatment related mortality with excellent response to treatment. We suggest that this strategy may be promising in effectively and safely delivering more cycles of chemotherapy without unneeded dose delay or reductions particularly in the setting of metastatic cancers where chemotherapy is the main line of treatment.

\section{Conflicts of Interest}

The authors declare no conflicts of interest.

\section{References}

[1] Dobrossy, L. (2005) Epidemiology of Head and Neck Cancer: Magnitude of the Problem. Cancer and Metastasis Reviews, 24, 9-17. https://doi.org/10.1007/s10555-005-5044-4

[2] Cancer Network (2005) Head and Neck Cancer, Head and Neck Tumors. http://www.cancernetwork.com/head-neck-cancer/head-and-neck-tumors/

[3] Ibrahim, A., Khaled, H., Mikhail, N., Baraka, H. and Kamel, H. (2014) Cancer Incidence in Egypt: Results of the National Population-Based Cancer Registry Program. Journal of Cancer Epidemiology, 2014, 437971. https://doi.org/10.1155/2014/437971

[4] Vermorken, J., Remenar, E., van Herpen, C., Gorlia, T., Mesia, R., Degardin, M., et al. (2007) Cisplatin, Fluorouracil, and Docetaxel in Unresectable Head and Neck Cancer. The New England Journal of Medicine, 357, 1695-1704. https://doi.org/10.1056/NEJMoa071028

[5] Posner, M., Hershock, D., Blajman, C., Mickiewicz, E., Winquist, E., Gorbounova, V., et al. (2007) Cisplatin and Fluorouracil Alone or with Docetaxel in Head and Neck Cancer. The New England Journal of Medicine, 357, 1705-1715. https://doi.org/10.1056/NEJMoa070956

[6] Healio (2010) HemOnc Today, Maximum Tolerated Exposure: A More Rational Approach to Drug Dosing. https://www.healio.com/hematology-oncology/news/print/hemonc-today 
[7] Saif, M., Choma, A., Salamone, S. and Chu, E. (2009) Pharmacokinetically Guided Dose Adjustment of 5-Fluorouracil: A Rational Approach to Improving Therapeutic Outcomes. Journal of the National Cancer Institute, 101, 1543-1552. https://doi.org/10.1093/jnci/djp328

[8] Lustig, V., Rosing, H., Van Warmerdam, L., Huizing, M.T., Ten Dokkel Huinink, W., Dubbelman, A., et al. (1997) Limited Sampling Models for the Pharmacokinetics of Docetaxel. Clinical Drug Investigation, 13, 247-254. https://doi.org/10.2165/00044011-199713050-00004

[9] Kaldate, R., Haregewoin, A., Grier, C., Hamilton, S.A. and McLeod, H.L. (2012) Modeling the 5-Fluorouracil Area under the Curve versus Dose Relationship to Develop a Pharmacokinetic Dosing Algorithm for Colorectal Cancer Patients Receiving FOLFOX6. Oncologist, 17, 296-302. https://doi.org/10.1634/theoncologist.2011-0357

[10] Engels, F., Loos, W., van der Bol, J., de Bruijn, P., Mathijssen, R.H., Verweij, J., et al. (2011) Therapeutic Drug Monitoring for the Individualization of Docetaxel Dosing: A Randomized Pharmacokinetic Study. Clinical Cancer Research, 17, 353-362. https://doi.org/10.1158/1078-0432.CCR-10-1636

[11] Eisenhauer, E., Therasse, P., Bogaerts, B., Schwartz, L.H., Sargent, D., Ford, R., et al. (2009) New Response Evaluation Criteria in Solid Tumors: Revised RECIST Guideline (Version 1.1). European Journal of Cancer, 45, 228-247. https://doi.org/10.1016/j.ejca.2008.10.026

[12] Basch, E., Reeve, B., Mitchell, S., Clauser, S.B., Minasian, L.M., Dueck, A.C., et al. (2014) Development of the National Cancer Institute's Patient-Reported Outcomes Version of the Common Terminology Criteria for Adverse Events (PRO-CTCAE). Journal of the National Cancer Institute, 106, dju244. https://doi.org/10.1093/jnci/dju244

[13] Posner, M. (2007) Evolving Strategies for Combined-Modality Therapy for Locally Advanced Head and Neck Cancer. Oncologist, 12, 967-974.

https://doi.org/10.1634/theoncologist.12-8-967

[14] Santini, J., Milano, G., Thyss, A., Renee, N., Viens, P., Ayela, P., et al. (1989) 5-FU Therapeutic Monitoring with Dose Adjustment Leads to an Improved Therapeutic Index in Head and Neck Cancer. British Journal of Cancer, 59, 287-290. https://doi.org/10.1038/bjc.1989.59

[15] Fety, R., Rolland, F., Barberi-Heyob, M., Hardouin, A., Campion, L., Conroy, T., et al. (1998) Clinical Impact of Pharmacokinetically-Guided Dose Adaptation of 5Fluorouracil: Results from a Multicentric Randomized Trial in Patients with Locally Advanced Head and Neck Carcinomas. Clinical Cancer Research, 4, 2039-2045.

[16] Gamelin, E., Delva, R., Jacob, J., Merrouche, Y., Raoul, J.L., Pezet, D., et al. (2008) Individual Fluorouracil Dose Adjustment Based on Pharmacokinetic Follow-Up Compared with Conventional Dosage: Results of a Multicenter Randomized Trial of Patients with Metastatic Colorectal Cancer. Journal of Clinical Oncology, 26, 2099-2105. https://doi.org/10.1200/JCO.2007.13.3934

[17] Fang, L., Xin, W., Ding, H., Zhang, Y., Zhong, L., Luo, H., et al. (2016) Pharmacokinetically Guided Algorithm of 5-Fluorouracil Dosing, a Reliable Strategy of Precision Chemotherapy for Solid Tumors: A Meta-Analysis. Scientific Reports, 6, 25913. https://doi.org/10.1038/srep25913

[18] Ten Tije, A.J., Verweij, J., Carducci, M.A., Graveland, W., Rogers, T., Pronk, T., et al. (2005) Prospective Evaluation of the Pharmacokinetics and Toxicity Profile of Docetaxel in the Elderly. Journal of Clin ical Oncology, 23, 1070-1077. https://doi.org/10.1200/JCO.2005.03.082 